\title{
Depression in Diabetes: A cross sectional survey among patients attending Diabetes Clinic in Kathmandu
}

\author{
Bhattarai $\mathrm{J}^{1}$, Kunwar $\mathrm{A}^{2}$, Shrestha $\mathrm{P}^{3}$, Acharya $\mathrm{S}^{4}$, Sah RP \\ ${ }^{1}$ Cosnultant Endocrinologist, Metro Kathmandu Hospital, Kathmanndu, Nepal, ${ }^{2}$ Consultant Psychiatry, \\ Metro Kathmandu Hospital, Kathmanndu, Nepal , ${ }^{3}$ Pscyhologist, Department of Psychology and \\ Philosophy, Trichandra Multiple Campus, Ghantaghar, Kathmandu, Nepal , ${ }^{4}$ MSc. Public Health, \\ Assistant Consultant, Oxford Policy Management, Oxford Brookes University,UK, ${ }^{5}$ Psychologist, Kanti \\ children Hospital, Kathmandu, Nepal
}

\begin{abstract}
Background: Depression, being a leading cause of disability, is a common illness affecting an estimated 350 million people affected worldwide and is a major contributor to the global burden of disease ${ }^{3}$. Depression is a significant comorbid condition prevalent in people with diabetes and adversely affects health outcomes. Methods: A cross sectional study was conducted on 434 patients in Metro Polyclinic situated in Kathmandu district of Nepal. Metro polyclinic was purposively selected as the sampling frame for this study as this polyclinic receives significant number of diabetes patients coming in from various regions of Nepal. Results: Among type -1 diabetes $55 \%$ had depression whereas $45 \%$ were normal. Among Type -2 diabetes $31 \%$ of them had depression whereas $69 \%$ had no depression. Among a total of 434 study sample, 425 were suffering from Type- 2 diabetes while only nine of them were suffering from Type-1 diabetes. Of those who were suffering from Type-2 diabetes, 13 had severe depression, 27 had moderate depression, 85 had mild depression and 300 had normal range of depression. Conclusion: This study sheds the importance of looking for depression in Nepali diabetes patients. It has been shown that without identifying co-morbid depression and treating it, most of the patient will have poor prognosis.
\end{abstract}

Keywords: Depression, Diabetes, Disability

\section{Background:}

Diabetes is a chronic disease, that leads to an increased concentration of glucose in the blood (hyperglycemia) ${ }^{1}$. According to International Diabetes Federation in 2017, approximately 425 million adults (20-79 years) in the world were living with diabetes2. Depression, being a leading cause of disability, is a common illness affecting an estimated 350 million people affected worldwide and is a major contributor to the global burden of disease ${ }^{3}$. Depression is a significant comorbid

\section{Correspondence Author}

Dr Jyoti Bhattarai

Cosnultant Endocrinologist

Metro Kathmandu Hospital, Kathmanndu, Nepal condition prevalent in people with diabetes and adversely affects health outcomes. The combination of diabetes and depression is associated with decrease in functional abilities and self-care. The relationship between depression and diabetes appears to be bi-directional, i.e. those with diabetes are at increased risk for developing depression; and conversely, those with depression are at increased risk for developing diabetes ${ }^{4}$. A study showed that depression is associated with a $60 \%$ increased risk of type 2 diabetes ${ }^{5}$. Another meta-analysis showed depressed adults having 37\% increased risk of developing type 2 diabetes mellitus ${ }^{6}$. Compared with non-diabetes patients controls, people with type 2 diabetes have a $24 \%$ increased risk of developing depression? ${ }^{7}$. People with diabetes 
exhibit relatively high rates of diabetes specific distress, affective and anxiety disorders. For the people diagnosed with diabetes, the addition of depression serves to increase symptom burden, diabetes-related complications, unemployment, work-related disability, and healthcare costs ${ }^{8}$. Moreover, depression among individuals with diabetes has also been associated with potential socio-demographic, lifestyle, and clinical factors. The contributions of socioeconomic status, marital status, obesity, smoking habits, and physical limitations and inactivity have been extensively tested ${ }^{9}$.

The Objective of this study was assess the prevalence of depression among patients with diabetes in outpatient clinic at Metro Polyclinic in Kathmandu:

\section{Methods:}

A cross sectional study was conducted on 434 patients in Metro Polyclinic situated in Kathmandu district of Nepal. Metro polyclinic was purposively selected as the sampling frame for this study as this polyclinic receives significant number of diabetes patients coming in from various regions of Nepal. This study used previously collected data from individual diabetes patients who came to Metro Polyclinic to receive treatment or counselling to manage their medical condition.

This study was conducted after the ethical approval from Nepal Health Research Council. Participants were explained about the research detail, its significance, the benefit and harm in Nepali language before obtaining the consent, their queries were answered.

Data were collected from diabetes patients within a certain point in time (approximately three months) by data collectors only after obtaining written and verbal consent from each patient. A structured questionnaire was prepared and pretested for collecting information regarding socio-demographic characteristics of the patients. Patient Health Questionnaire (PHQ)-9 scale was used to assess the prevalence of depression. All questions included in PHQ-9 scale were converted to Nepali language to maintain the external validity of the questionnaire. PHQ-9 scale has been used by many scholars to measure depression specifically in outpatient care ${ }^{10}$ PHQ-9 scale has a sensitivity of $88 \%$ and a specificity of $88 \%$ for major depressive disorders and it has a high internal consistency ${ }^{11}$

\section{Results:}

This cross-sectional study showed that the prevalence of depression was $30 \%$ among diabetes patients coming in to receive treatment or counselling from Metro polyclinic.

Table 1.1 Socio-demographic characteristics of the patients

\begin{tabular}{|c|c|c|c|c|}
\hline S.N & Domain & Sub- Domain & Frequency & Percentile \\
\hline \multirow[t]{5}{*}{1} & \multirow[t]{5}{*}{ Religion } & Hindu & 400 & 92.2 \\
\hline & & Buddhist & 25 & 5.8 \\
\hline & & Muslim & 1 & .2 \\
\hline & & Christian & 3 & .7 \\
\hline & & Others & 5 & 1 \\
\hline \multirow[t]{6}{*}{2} & \multirow[t]{6}{*}{ Ethnicity } & Dalit & 6 & 1.4 \\
\hline & & Janajaati & 122 & 28.1 \\
\hline & & Madhisi & 31 & 7.1 \\
\hline & & Muslim & 1 & .2 \\
\hline & & Brahmin/Chhetri & 272 & 62.7 \\
\hline & & Others & 2 & .5 \\
\hline \multirow[t]{4}{*}{3} & \multirow[t]{4}{*}{ Marital Status } & Unmarried & 10 & 2.3 \\
\hline & & Married & 401 & 92.4 \\
\hline & & Separated & 6 & 1.4 \\
\hline & & Widow & 17 & 3.9 \\
\hline \multirow[t]{2}{*}{4} & \multirow[t]{2}{*}{ Diabetes Type } & type- 1 & 9 & 2.1 \\
\hline & & type- 2 & 425 & 97.9 \\
\hline \multirow[t]{9}{*}{5} & \multirow[t]{9}{*}{ Occupation } & Housewife & 126 & 29.0 \\
\hline & & Unemployed & 6 & 1.4 \\
\hline & & Government service & 68 & 15.7 \\
\hline & & Non-government & 33 & 7.6 \\
\hline & & Agriculture & 31 & 7.1 \\
\hline & & Business & 104 & 24.0 \\
\hline & & Labor & 8 & 1.8 \\
\hline & & Studying & 4 & 0.9 \\
\hline & & Others & 54 & 12.4 \\
\hline \multirow[t]{2}{*}{6} & \multirow[t]{2}{*}{ Gender } & Female & 182 & 41.9 \\
\hline & & Male & 252 & 58.1 \\
\hline
\end{tabular}


Table 1.2 Range of depression amongst patients

\begin{tabular}{|l|l|l|}
\hline \multicolumn{1}{|c|}{$\begin{array}{c}\text { Range of } \\
\text { Depression }\end{array}$} & Frequency & $\begin{array}{c}\text { Percentage } \\
(\%)\end{array}$ \\
\hline Normal & 304 & 70.0 \\
\hline Mild level & 89 & 20.5 \\
\hline Moderate level & 28 & 6.5 \\
\hline Severe level & 13 & 3.0 \\
\hline Total & 434 & 100 \\
\hline
\end{tabular}

Table 1.3 Range of depression among diabetes patient according to type of diabetes

\begin{tabular}{|c|c|c|c|c|c|}
\hline \multirow{2}{*}{$\begin{array}{l}\text { Type of } \\
\text { Diabetes }\end{array}$} & \multicolumn{4}{|c|}{ Range of Depression } & \multirow{2}{*}{$\begin{array}{c}\text { Total } \\
\text { number of } \\
\text { patient }\end{array}$} \\
\hline & Normal & Mild & Moderate & Severe & \\
\hline Type-1 & 4 & 4 & 1 & 0 & 9 \\
\hline Type-2 & 300 & 85 & 27 & 13 & 425 \\
\hline Total & 304 & 89 & 28 & 13 & 434 \\
\hline
\end{tabular}

Among type -1 diabetes 55\% had depression where as $45 \%$ were normal. Among Type -2 diabetes $31 \%$ of them had depression where as $69 \%$ had no depression.

Among a total of 434 study sample, 425 were suffering from Type-2 diabetes while only nine of them were suffering from Type-1 diabetes. Of those who were suffering from Type-2 diabetes, 13 had severe depression, 27 had moderate depression, 85 had mild depression and 300 had normal range of depression. In contrary, of those suffering from Type-1 diabetes, none of them had severe depression, only one of them had moderate depression, four of them had mild depression and four of them had normal depression.

\section{Discussion:}

In this study, the prevalence of depression among diabetes patients was $30 \%$. In other studies conducted in similar setting in other countries, prevalence of depression was found to be similar. For instance, in a study conducted in Vietnam, prevalence of depression among diabetes patient was $23.2 \% 12$ In addition in another study conducted in Saudi Arabia which used PHQ-9 scale, the prevalence of depression was 37 percent $^{13}$ Of those, $23 \%$ had mild, $9 \%$ had moderate and $5 \%$ had severe depression which is similar to this study. In this study, $19.6 \%$ had mild, $6.2 \%$ had moderate and $3 \%$ had severe depression.

There is significant gap on research concerning depression among diabetes patients in Nepal. The study aims to add on to the evidence and initiate further research on this topic. However, there are several limitations of this study. First, this study purposively selected Metro Polyclinic as its sampling frame which might affect the generalisability of this study. Second, a crosssectional method was used in this study which only considers a certain segment of population at certain point in time. Either cohort or experimental studies which assess diabetes patients for a longer a period of time has better external validity than cross-sectional study to study the prevalence of depression among diabetes patients. Third, this study undermined the association of depression according to socio-demographic characteristics of patients. Certain confounding variables mainly related with socio-demographic characteristics might skew the findings of the study.

\section{Conclusion:}

This study sheds the importance of looking for depression in Nepali diabetes patients. It has been shown that without identifying co-morbid depression and treating it, most of the patient will have poor prognosis. This cross sectional study highlights the important correlation between diabetes and depression in Nepali population. Further controlled prospective studies are needed for future direction.

\section{Abbreviations:}

Diabetes Mellitus: DMT2DM: Type 2 Diabetes Mellitus OPD: Outpatient department, PHQ: Patient Health Questionnaire

\section{Competing Interests}

The authors declare no competing interests. 


\section{Funding}

Metro Kathmandu Hospital

\section{Author's Contribution}

$\mathrm{JB}, \mathrm{AK}$, PS were involved in concept and design; acquisition of data was done by JB, AK, PS, SA, RS; JB, AK, PS, SA, RS were involved in analysis and interpretation; JB and RS drafted the article; Final approval of the manuscript was done by all authors.

\section{End Note}

PHQ-9 is a depression module which scores each of the 9 DSM-IV criteria as " 0 " (not at all) to " 3 " (nearly every day). Depression severity is given as 0-4 none, 5-9 mild, 10-14 moderate, 15-19 moderately severe, $20-27$ severe

\section{References:}

1. World Health Organization (WHO), (2014), Health Topics Diabetes [Online, Available at http://who.int/topics/diabetes_mellitus/en/] (Accessed on 10 September 2014)

2. International Diabetes Federation. Diabetes atlas 8th edition po2017

3. World Health Organization (WHO), (2014), Media Centre, Depression [Online, Available at [http://who.int/mediacentre/factsheets/fs369/ en/] (Accessed on 10 September 2014)

4. Holt RI et al Diabetes and Depression Curr Diab Rep. 2014 Jun; 14(6): 491.

5. Mezuk B, Eaton WW, Albrecht S, Golden $\mathrm{SH}$. Depression and type 2 diabetes over the lifespan: a meta-analysis. Diabetes Care. 2008; 31:2383-90. [PubMed: 19033418]
6. Knol MJ, Twisk JW, Beekman AT, Heine RJ, Snoek FJ, Pouwer F. Depression as a risk factor for the onset of type 2 diabetes mellitus. A meta-analysis. Diabetologia. 2006; 49:837-45. [PubMed: 16520921]

7. Nouwen A, Winkley K, Twisk J, Lloyd CE, Peyrot M, Ismail K, et al. Type 2 diabetes mellitus as a risk factor for the onset of depression: a systematic review and metaanalysis. Diabetologia. 2010; 53:2480-6. [PubMed: 20711716]

8. Engum, A, et.al., (2005), Depression and Diabetes: A large population-based study of socio-demographic, lifestyle and clinical factors associated with depression in type 1 and type 2 diabetes, Diabetes Care, Vol.28, No.8, August 20059

9. Raval, A. et.al., (2010), Prevalence and Determinants of Depression in Type 2 Diabetic patients in a tertiary health care center, Indian J Med Res 132, August 2010, 195-200

10. https://pubmed.ncbi.nlm.nih.gov/11556941/ ; https://pubmed.ncbi.nlm.nih.gov/18186994/ ; https://pubmed.ncbi.nlm.nih.gov/24130903/ ; https://pubmed.ncbi.nlm.nih.gov/22710475/

11. https://www.apa.org/pi/about/publications/ caregivers/practice-settings/assessment/ tools/patient-health\#: :text=PHQ\%2D9\%20 scores $\% 20 \% 3 \mathrm{E} \% 2010 \% 20 \mathrm{had}$, been $\% 20$ shown $\% 20$ to $\% 20$ be $\% 20$ high.

12. https://www.dovepress.com/depressionamong-patients-with-type-2-diabetes-mellitusprevalence-and-peer-reviewed-fulltext-articleDMSO

13. https://www.ncbi.nlm.nih.gov/pmc/articles/ PMC7322613/ 